\title{
editorial
}

\section{Freedom and responsibility}

B eing an academic scientist is a great job. Notwithstanding the long hours, pressure to publish and stony career path-which are all characteristics of other jobs, too-research offers a degree of freedom that few occupations can match. Who else is paid to satisfy his or her curiosity about the world? Who else is given money to conduct research that has no immediate relevance or applicability - understanding the molecular basis of flower colour, counting species on a remote Pacific island, or watching atoms smashing into each other at the speed of light? Who else gets paid to fly to beautiful locations to spend a week discussing their favourite topics? Who else has access to the kind of fancy tools and technologies-observatories, electron microscopes or super computers-that make gadget nerds jealous?

Yes, there is the implicit expectation by the public that scientific research will eventually create new products, services and jobs; yes, there are debates about the purported dangers of genetically modified crops or the moral status of embryonic stem cells; and yes, getting more money has to be justified by past successes. Still, most taxpayers - who ultimately fund academic research-accept that scientists are best left alone to make discoveries that eventually lead to commercial products or social advances. In short, scientists are given public money, with few strings attached.

This freedom, however, comes with a price: responsibility. If governments invest a sizeable chunk of their budget into basic, curiosity-driven research, without scrutinizing how every cent is being spent, they do so because they and the public trust scientists to handle this money responsibly-ostensibly more than investment bankers.

Thus, the impact of research fraud goes beyond wasting time, money and resources, and beyond misleading the research community. As public funding of scientific research is based on trust, the minority of researchers who commit fraud or falsify results threaten to destroy the very foundation of public support for science. Highly publicized cases of misconduct in which scientists have obviously misused research funds on a massive scale-such as the Hwang case in South Korea, or the Poehlman case in the USA-erode the trust placed in scientists. Above all else, this is why the scientific community has little tolerance for fraudsters and hucksters in their midst: those found guilty tend to find that their careers in academic research are over.

These major cases, however, are just the tip of the iceberg. Many cases of suspected data falsification or fraudulent image manipulation never see the light of day. Moreover, there is also a large, grey area of questionable research practices that are not outright misconduct, but that when combined come very close, or represent the first steps on a slippery slope towards more reprehensible behaviour.

The most efficient measures to prevent scientific misconduct are awareness -notably, self-awareness-education and transparency. Every scientist should follow the two fundamental rules of science, described by US cosmologist Carl Sagan: "First: there are no sacred truths; all assumptions must be critically examined; arguments from authority are worthless. Second: whatever is inconsistent with the facts must be discarded or revised. We must understand the Cosmos as it is and not confuse how it is with how we wish it to be."

Since universities train future scientists, they have a major role to play, both in teaching proper research conduct and in creating working environments that nurture open collaboration, rather than unhealthy competition that can easily lead to cutting corners. Senior scientists must be aware of their function as role models for junior researchers and students, and must live up to the standards of proper research. It is the task of the whole scientific community to maintain and advertise the proper conduct of research to preserve trust in their enterprise. The importance of proper conduct, though, is too often and too easily forgotten.

This issue of EMBO reports contains a selection of articles that explore the causes and consequences of scientific misconduct. On page 745, Nicholas Steneck, Director of the Research Ethics and Integrity Program of the Michigan Institute for Clinical and Health Research, stresses the role of each and every scientist in establishing and maintaining proper conduct of research. Brian Martinson, a senior research investigator at the Health Partners Research Foundation, explains how structural and financial factors at universities can lead to unhealthy competition, and thereby increase the risk of misconduct (page 758). Ulrike Beisiegel was spokesperson of the German ombudsman for science before she became President of Göttingen University. She speaks about the structural causes of competition and misconduct, and about how to increase awareness among the community and, in particular, the younger generation of scientists (page 754).

We hope that these articles stimulate our readers to think about the causes and consequences of research misconduct, and provoke open discussions. Honesty and openness are fundamental to the scientific endeavour, and it is the duty of every scientist to follow proper research practices. The funding of basic, curiosity-driven research rests on the trust placed in scientists, but this trust can be easily eroded.

\section{Holger Breithaupt}

EMBO reports (2011) 12, 744 .

doi:10.1038/embor.2011.145 